\title{
Study on the application of the QEC (Quick Exposure Check) on the ergonomic risks assessment in the industrial field
}

\author{
Adrian Ispăsoiu ${ }^{1 *}$, Ioan Milosan ${ }^{1}$, Dorin Senchetru ${ }^{2}$, Teodor Machedon-Pisu ${ }^{3}$, Ana Maria \\ Florina Ispăsoiu ${ }^{4}$, and Cristina Meiță \\ ${ }^{1}$ Department of Materials Science, Transilvania University of Brasov, Romania, 500036 Brasov, \\ Romania \\ ${ }^{2}$ Territorial Labor Inspectorate of Brasov County, 500080 Brasov, Romania \\ ${ }^{3}$ Department of Materials Engineering and Welding, Transilvania University of Brasov, 500036 \\ Brasov, Romania \\ ${ }^{4}$ Maastricht University, Science Programme, Kapoenstraat 2, $6211 \mathrm{KW}$, Maastricht, Netherlands \\ ${ }^{5}$ HSE Manager Bog'Art, 010131 Bucharest, Romania
}

\begin{abstract}
In Romania there are approximately 200,000 employees in the automotive industry, ranking $4^{\text {th }}$ in the EU, after Germany, France and Poland. Many workers in these industries complain of musculoskeletal disorders caused by the high pace of work, awkward positions, handling of masses, etc., often being cumulated. It is therefore essential that these risks related to ergonomics are correctly identified, assessed and treated. The Quick Exposure Check (QEC) is an advanced exposure assessment method that combines observational assessment and self-reporting. This paper presents an applied study of the QEC methodology, a technique based on questions that will be answered by both the observer and the evaluated worker. The research analysed the activity of manually transferring metal parts (components from the automotive industry) from a trolley on a conveyor belt for processing and, vice versa, taking the processed parts from a conveyor belt and placing them on a trolley, because these activities generate many risks to workers' health. Analysing the results of the evaluation of the ergonomic risks generated by incorrect and / or awkward positions during the activities, using the QEC method, it is found that there are some areas of the body that are much affected during these activities.
\end{abstract}

\section{Introduction}

The term ergonomics comes from the Greek words ergon (work) and nomos (rules) and means the science of work. Ergonomics is an interdisciplinary science because it integrates knowledge from a multitude of subjects, such as: anatomy, physiology, anthropometry, technical sciences, psychology, sociology, occupational hygiene, etc.

The International Ergonomics Association (IEA) uses the following definition: "ergonomics is the scientific subject concerned with the interactions between people and

\footnotetext{
*Corresponding author: adrian.ispasoiu@unitbv.ro
} 
other elements of a system and applies theories, principles, information and design methods in order to optimize human's well-being and overall system performance" [1-2].

Ergonomic risk assessment is a process which consists of identifying situations in which workers may be subject to ergonomic risks, estimating and assessing these risks using an appropriate methodology. It is a systematic examination of all aspects of work, in order to establish:

- the causes of possible harming or injuries,

- the possibilities to eliminate ergonomic risk factors and, if this is not possible,

- the prevention or protection measures that are or must be implemented to control ergonomic risks.

Musculoskeletal disorders (MSD) are an injury or disorder of the musculoskeletal system resulting from repeated exposure to various hazards and/or risk factors in the workplace [3-8]. MSDs are found in several industries and professions, where they can have rates up to three or four times higher than other industries and professions, and the automotive industry it is part of such industries [9]. And in Romania the rate of employee's number which is affected by MSD is to high [10].

Quick Exposure Check (QEC) is a method to prevent or reduce the risk to workers. A large number of researchers have turned their attention to this method. Some of them focused on industry domains such us: oil [11-16]. Other researchers are turning their attention to for assessing exposure to risk factors for work-related musculoskeletal disorders [17-19], in constructions field [20], or to test QEC in different occupational groups [21-22], like among motorbike riders [23], for the development of action levels for the 'quick exposure check' (QEC) system [17-18, 24] and also to adaptation of the of Quick Exposure Check Questionnaire to the specific situations of work [19, 25].

This paper briefly presents the Quick Exposure Check (QEC) methodology and an example of its application, which is an observation tool developed for occupational safety and health $(\mathrm{OSH})$ specialists to assess exposure to ergonomic risks, especially the risk of musculoskeletal disorders, work-related and to provide a basis for taking measures to improve ergonomics in workplaces where there are problems.

\subsection{What is the problem}

In the European Union there are approx. 2.7 million people in the automotive industry (and the number of those working in the automotive industry in Europe in total is of 14.6 million people, namely $6.7 \%$ of the total EU workforce). In Romania there are about 200,000 employees in this industry. It means that out of the total number of employees in production in the national economy, about $16 \%$ is represented by employees in production in the automotive industry [10]. Many workers in these industries complain of musculoskeletal disorders caused by the high pace of work, awkward positions, handling of masses, etc., often being cumulated. It is therefore essential that these risks related to ergonomics are correctly identified, assessed and treated.

\subsection{Purpose}

The main purpose of ergonomic risk assessment is to protect the safety and health of workers. Ergonomic risk assessment helps to reduce the possibility of injury to workers as a result of activities performed in poor ergonomic conditions. It also helps maintain the company's competitiveness and productivity. 


\subsection{Objectives}

The present study evaluated the effect of posture and rhythm of work during working program on musculoskeletal disorders.

The objectives of the ergonomic risk assessment are:

a. identification of situations that may affect workers from a musculoskeletal point of view within the selected activities;

b. identification of awkward working positions;

c. identification of repetitive movements and forced actions;

d. identification of situations where is poor work organization;

e. estimation and evaluation of all these risks factors;

f. and at the end, proposing prevention and protection measures;

from workstations in the production hall of car parts factories.

Exposure to these factors causes effects on the worker (for example, overload of some muscles and joints, decreased blood flow or local muscle fatigue). If preventive measures are not taken in time, these risk factors can generate MSDs with the worst effects.

\section{Ergonomic approach}

Ergonomics is a method of adapting a work area to the worker [9]. Ergonomics aims to reduce the amount of effort / pressure exerted on the body of the worker to maximize efficiency in productive work but at the same time reducing disease. This is done by analyzing the work process, by arranging the work area, by providing appropriate tasks, by observing the parameters of the work environment, by adapting to the appropriate heights or angles of the work plans so that the worker performs the necessary work tasks in conditions of comfort and safety. Physical requirements are analyzed and potential risk factors that are associated with the development of musculoskeletal disorders (MSDs) on workers are identified.

Therefore, the approach of working conditions based on the observance of ergonomic principles for the reduction of musculoskeletal disorders (MSD) requires a global analysis and evaluation of all elements of the work system so that optimal results are obtained.

It turns out that both the main and obvious problems will be taken into account, but also those problems that together become important through the cumulative negative effects. Such problems may be: workload design taking into account worker-equipment interfaces, worker training requirements, work organization and legal or internal requirements and, including, individual issues (such as family issues or work motivation) and culture organizational as a whole [26]. This approach ensures that workers will be satisfied at work and the work itself becomes a pleasant activity.

\section{Ergonomic risk factors}

Ergonomic risk factors are those factors that are found in the work system (which also includes workload) that put a high biomechanical pressure on the worker's body. The most important factor that can lead to MSD is the imbalance between the degree of fatigue of the body (which may be local) and the ability of the individual to recover from this fatigue [4].

These conditions can be prevented by understanding and applying the basic ergonomic principles. Every worker must know and be aware of the ergonomic risk factors related to his work tasks and the methods to diminish the effects of these risk factors [4].

In many industrial activities, especially those carried out on automatic / semi-automatic manufacturing lines, there are a number of ergonomic risk factors. 


\subsection{Strehght}

The force represents the amount of effort exerted by the muscles and all work tasks require the worker to apply a certain force with a certain part of the body and in certain positions. When an action requires the application of too much force to a particular muscle, it can affect the worker's muscles and / or joints.

When analyzing the force required by the worker to perform an activity, we must consider other factors that may adversely affect the worker's body such as:

- supported weight (mass, direct pressure)

- time to be applied (duration)

- how many times to exercise in a time interval (frequency)

- the posture adopted when this force is applied (posture).

\subsection{Posture}

Posture is the position of different parts of the body during an activity. A good posture is as close as possible to the middle of the maximum area of movement for a joint. This is also called a "neutral" posture. If a joint approaches each end of its range of motion (that is, the farther it is from neutral), then the posture becomes more awkward and more pressure is exerted on the muscles, tendons and ligaments around the joint.

\subsection{Repeated movements}

When the same muscles, tendons, joints, etc. are used repeatedly, with few rest breaks, the risk of MSD affections increases. Repetitive tasks can cause muscle fatigue, tissues damage, pain and discomfort. They can be felt even if the force exerted is small and the rest of the working conditions are good.

\section{QEC history and argumentation for choosing the QEC for the assessed activities}

QEC is a tool for assessing the risk of musculoskeletal disorders based mainly on the analysis of exposure to risk factors. It was developed at the Robens Center for Health Ergonomics in the UK by G. Li and P. Buckle (1998) and improved several times over the years. Over time, QEC has proven to be a valid, sensitive and reliable tool in ergonomic risk assessment. The QEC is applicable for use in a wide range of activities, is easy to use and has the advantage that workers' activities are not interrupted during the assessment. The QEC assessment considers several aspects that represent musculoskeletal risk factors, such as: movement (from static / dynamic position), frequency, subjective forces, manipulated weight, vibrations and work rhythm. QEC analyzes the observer's findings and the worker's answers in a closed set of questions, which provides a high degree of objectivity [11].

There where analysed the information found on the spot and those obtained from a sample of 60 workers from different factories in the automotive field, and it was observed that the workers, in carrying out the activities subject to evaluation, use much of the upper body, the legs being straight and used just for support and small walks. It has also been observed that workers are affected, from an ergonomic point of view, by: the forced position of the torso, arms and hands and the position of the neck, as well as the work rhythm, frequency and duration of movements. 
These findings indicated the QEC as an appropriate tool to carry out ergonomic risk assessment for a range of activities where workers face ergonomic issues, affecting their health.

Characteristics of the QEC method:

- Treat activities individually

- Includes answers from the assessor and from the worker

- Takes into consideration:

- Back, Shoulder, Wrist / Arm, Neck

- The pace of work

- Vibrations

- Stress.

\section{Development of the QEC}

The first step, presented in Figure 1, consists of the assessor's observation of the activity carried out and of questions addressed to the worker: QEC evaluates ergonomic risk factors taking into account physical, organizational and psychosocial factors. The ergonomic risk assessment using QEC methodology involves the steps shown in Fig. 1.

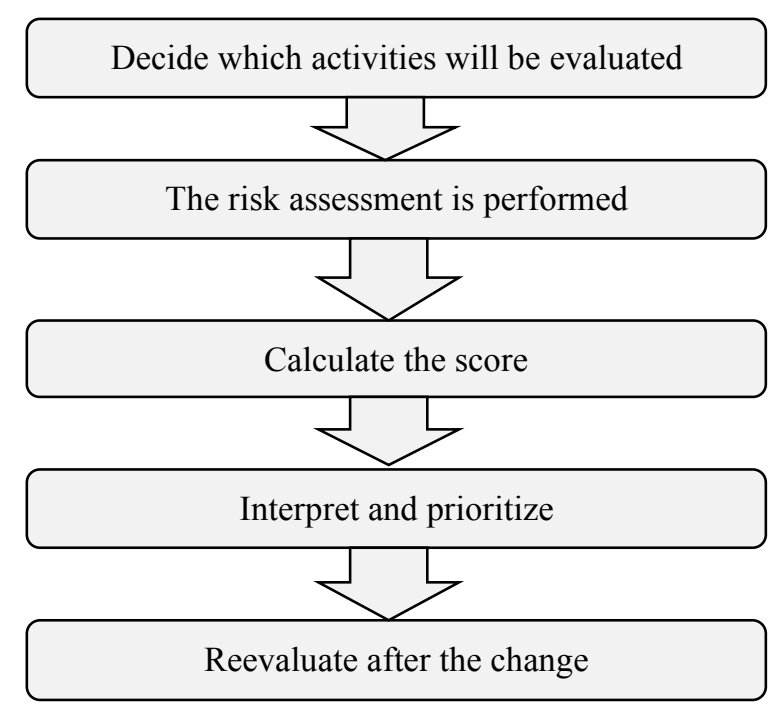

Fig. 1. Stages of ergonomic risk assessment [8].

The QEC assessment form contains 15 questions about torso and upper limb postures and movements, as well as manipulated masses, duration of a task, manual force, visual stress, vibrations and hand force, work rhythm and stress. Then a partial and total quantification of the risk is performed based on the calculation of a score, taking into account a certain area of the body. This score results from the combination of answers given by the observer and workers and was calculated by entering the score, derived from each question in the corresponding matrix [27].

\subsection{Analysis of the QEC evaluation form}

The questionnaire (Appendix 1) contains questions on various aspects related to the performance of a specific task to be analyzed, such as: description of the activity normally 
performed, duration and frequency of activity, discomfort of different parts of the body, rest duration and recovery time [28].

- QEC assesses the exposure of the components of the upper body (torso, arms, neck) with the highest risk to the most important risk factors for MSD.

- QEC was designed to assess the effect of exposure to musculoskeletal risk factors for the back, shoulders and arms, hands and wrists and neck at the time of evaluation, but also makes it possible to re-evaluate that activity so that the effectiveness of implemented ergonomic measures can be observed .

- The QEC involves both the assessor (ie the observer) in carrying out the assessment and the worker who is directly exposed to the risks associated with carrying out the task.

- The QEC is composed of two parts: the evaluation of the observer and the evaluation of the worker, and the data were collected right at the facilities (machines) where the activities (tasks) under analysis were carried out.

The questionnaire used is presented in Appendix 1 [27, 29].

The score of the QEC evaluation form is obtained as shown in the table in Appendix 2 [27, 29].

\subsection{Analysis of activities, workers, equipment and working methods}

For example, the activities of taking over some metal parts which had to be taken from the boxes and placed on the belt were observed, which are then transported to the processing plant. 6 workers who perform this activity at one of the lanes were observed and interviewed. These workers hold the position of production operator. The characteristics of these workers are presented in Table 1.

Table 1 Characteristics of workers

\begin{tabular}{|l|c|c|c|c|c|c|}
\hline \multirow{3}{*}{ Facility } & \multicolumn{7}{|c|}{ Workers } \\
\cline { 2 - 8 } & Code & Gender & Age & Height & Weight & Seniority in activity \\
\hline \multirow{4}{*}{ Tape power supply } & L1 & Female & 38 & $1,66 \mathrm{~m}$ & $62 \mathrm{~kg}$ & 4 years \\
\cline { 2 - 8 } & L2 & Male & 25 & $1,72 \mathrm{~m}$ & $70 \mathrm{~kg}$ & 2 years \\
\cline { 2 - 8 } & L3 & Male & 37 & $1,79 \mathrm{~m}$ & $96 \mathrm{~kg}$ & 4 years \\
\cline { 2 - 7 } & L4 & Male & 39 & $1,71 \mathrm{~m}$ & $88 \mathrm{~kg}$ & 3 years \\
\cline { 2 - 7 } & L5 & Male & 41 & $1,76 \mathrm{~m}$ & $90 \mathrm{~kg}$ & 3 years \\
\cline { 2 - 7 } & L6 & Male & 35 & $1,70 \mathrm{~m}$ & $77 \mathrm{~kg}$ & 4 years \\
\hline Note: L- worker & \multicolumn{70}{|c|}{} \\
\hline
\end{tabular}

Work schedule features: Operator

Work schedule: 8 hours/shift (break $30 \mathrm{~min}$ ); Monday - Sunday

Number of shifts: 3 ; 4 teams of 3 workers

Workers work 6 days with 2 days break

Brief description of the analysed activity:

Workers bend over the box to pick up pieces that weigh between $2.04 \mathrm{Kg}$ and $3.24 \mathrm{Kg}$ (Figure 2). During this operation, the worker has his torso bent (approx. 50 $-60^{\circ}$, depending on the height of the worker but also on the position of the parts in the box) and rotated. 


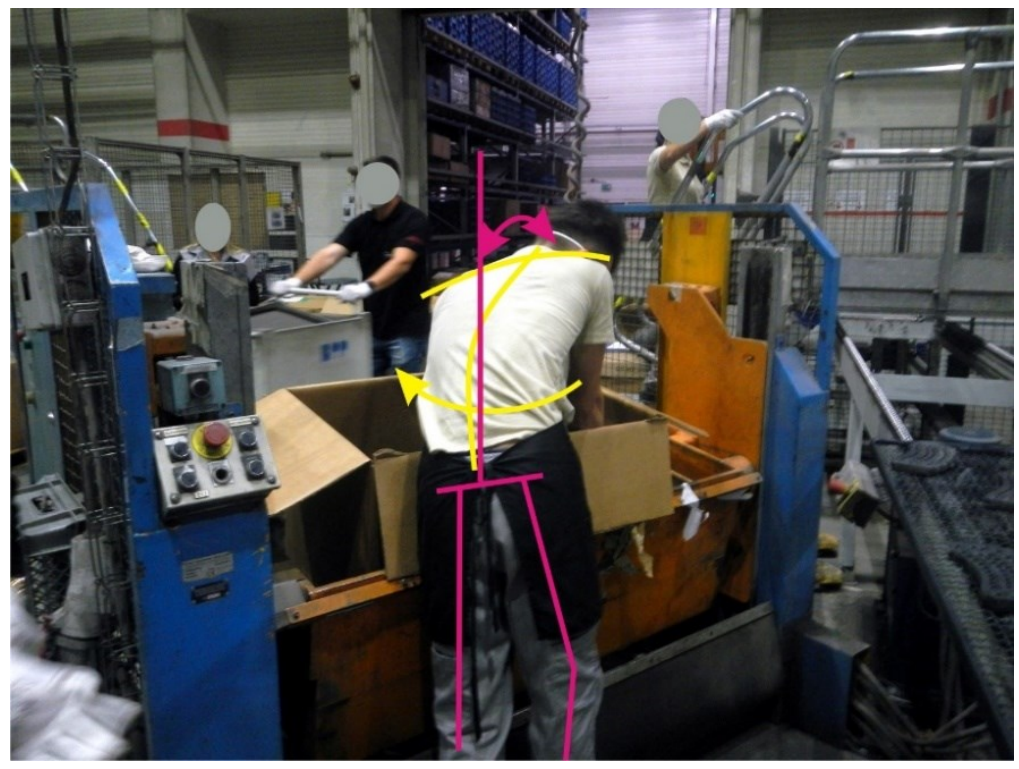

Fig. 2. Worker's position when picking up metal parts from the box

The worker usually rests on one leg, his shoulders are tensed and bent forward. Arms are outstretched and away from the body, reaching up to $90^{\circ}$.

Figure 3 shows the position of the worker during the placement of metal parts on the conveyor belt.

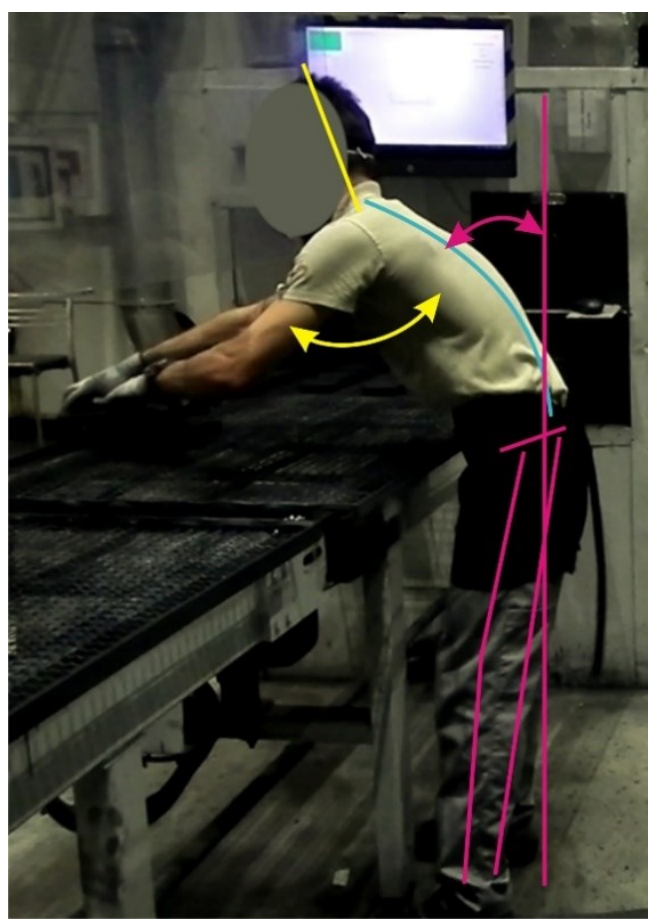

Fig. 3. Worker's position when placing metal parts on the conveyor belt 
The worker bends over the belt, the torso can have an angle of $90^{\circ}$, his shoulders are tensed and bent forward. The spine is curved. Arms are outstretched and away from the body, up to $110^{\circ}$.

The metal parts are gripped with the fingers, on their side, and the gripping force is quite high, so that the piece does not fall. The effects of this pressure and the areas of contact of the fingers with the metal parts can be seen in Figure 4.

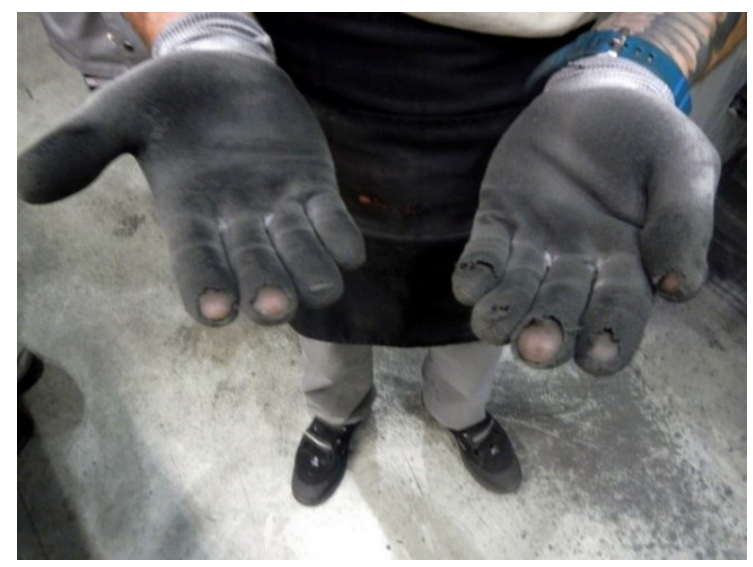

Fig. 4. Areas where metal parts are grip with the fingers

By analysing the wear of leather gloves (Figure 4), you can deduce the areas of grip of metal parts with one's fingers. In all activities, the parts are handled by hand. This implies a high and frequent pressure on the metal parts, which weigh between $2.04 \mathrm{Kg}$ and $3.24 \mathrm{Kg}$. It turns out that the hand and the phalanges of the fingers are subject to a high demand in terms of the tightening pressure.

Following the completion of the evaluation questionnaires and the performance of the calculations, according to the evaluation grids, the results in Table 2 were obtained.

Table 2. Results obtained by comparing the answers in the questionnaires with the QEC grids

\begin{tabular}{|l|l|c|c|c|c|c|c|}
\hline \multicolumn{3}{|c|}{ Activity / Worker } & \multicolumn{9}{|c|}{ Tape supply with metal parts } \\
\cline { 3 - 9 } \multicolumn{2}{|c|}{ Body part } & L1 & L2 & L3 & L4 & L5 & L6 \\
\hline \multirow{2}{*}{$\begin{array}{l}\text { Back/ } \\
\text { Torso }\end{array}$} & A. Position & A2 & A2 & A2 & A2 & A2 & A2 \\
\cline { 2 - 9 } & B. Frequency & B4 & B4 & B3 & B3 & B3 & B3 \\
\hline \multirow{2}{*}{ Shoulder / Arm } & C. Position & C1 & C2 & C1 & C1 & C1 & C1 \\
\cline { 2 - 9 } & D. Frequency & D2 & D3 & D2 & D2 & D2 & D2 \\
\hline \multirow{2}{*}{ Wrist / Hand } & E. Position & E2 & E2 & E1 & E1 & E2 & E2 \\
\cline { 2 - 9 } & F. Frequency & F2 & F2 & F1 & F1 & F1 & F1 \\
\hline G. Neck & Position & G3 & G3 & G2 & G2 & G2 & G2 \\
\hline H. Effort & H1 & H2 & H2 & H2 & H2 & H2 \\
\hline J. Time & J3 & J3 & J3 & J3 & J3 & J3 \\
\hline K. Force & K2 & K2 & K3 & K3 & K3 & K3 \\
\hline L. Visual accuracy & L1 & L1 & L1 & L1 & L2 & L2 \\
\hline M.Work machine vibrations & M1 & M1 & M1 & M1 & M1 & M1 \\
\hline N. Tool vibrations & N1 & N1 & N1 & N1 & N1 & N1 \\
\hline P. Rhythm & P2 & P3 & P1 & P1 & P2 & P2 \\
\hline Q. Stress & Q2 & Q2 & Q2 & Q2 & Q2 & Q2 \\
\hline
\end{tabular}




\begin{tabular}{|l|c|c|c|c|c|c|}
\hline \multirow{2}{*}{ Body part } & \multicolumn{6}{|c|}{ Tape supply with metal parts } \\
\cline { 2 - 8 } & L1 & L2 & L3 & L4 & L5 & L6 \\
\hline Total Exposure Back/Torso (Static) & - & - & - & - & - & - \\
\hline Total Exposure Back/Torso (Movement) & 30 & 36 & 32 & 32 & 32 & 32 \\
\hline Total Exposure Shoulder / Arm & 26 & 40 & 32 & 32 & 32 & 32 \\
\hline Total Exposure Wrist / Hand & 36 & 36 & 34 & 34 & 38 & 38 \\
\hline Total Exposure Neck & 16 & 16 & 14 & 14 & 16 & 16 \\
\hline Total Exposure Driving & 1 & 1 & 1 & 1 & 1 & 1 \\
\hline Total Exposure Vibrations & 1 & 1 & 1 & 1 & 1 & 1 \\
\hline Total Exposure Rhythm & 4 & 9 & 1 & 1 & 4 & 4 \\
\hline Total Exposure Stress & 4 & 4 & 4 & 4 & 4 & 4 \\
\hline
\end{tabular}

Table 2 shows some interesting values. For example, in terms of torso position, by observation, all workers have their torso (back) bent, twisted and bent sideways, to a moderate extent. From Appendix 1 to these observations corresponds the position with the value A2. On the other hand, workers answer the question "When performing this task, is the maximum level of force exerted by one hand?", Male workers - high (K3) and female workers - medium (k2). This is because men tend to grab 2-3 pieces at a time while women catch a single piece. Obviously these aspects have a significant impact on the body of workers.

\subsection{Performance analysis of QEC in ergonomic risk assessment}

QEC identifies quickly and accurately the level of exposure of various upper body components, such as the back, shoulders, arms, wrists and neck. The results of this method lead to the implementation of effective ergonomic measures to reduce the level of exposure, as can be seen in Table 3 .

Table 3. Exposure level table

\begin{tabular}{|c|c|}
\hline$*$ Exposure score (E) & Action \\
\hline$\leq 40 \%$ & Acceptable \\
\hline $41-50 \%$ & Investigate further \\
\hline $51-70 \%$ & $\begin{array}{r}\text { Investigate further and change the work situation } \\
\text { as soon as possible }(1-6 \text { months })\end{array}$ \\
\hline $70 \%$ & $\begin{array}{r}\text { Investigate and change the work situation } \\
\text { immediately (max. } 1 \text { month) }\end{array}$ \\
\hline
\end{tabular}

* The exposure level is obtained by dividing the total score obtained by the maximum score (where there is Xmax for the manual handling activity XmaxMH $=176$, for activities other than this, Xmax =162).

The following formula for calculating the exposure level (E) [28] represented in Equation (1) shall be used.

where:

$$
\mathrm{E}(\%)=\frac{\mathrm{X}}{\mathrm{Xmax}} \mathrm{X} 100 \%
$$

$\mathrm{X}=$ Total scores obtained for exposure to the risk of back, shoulder / arm, wrist and neck disorders obtained from the calculation matrices based on the answers to the questionnaire. $\mathrm{Xmax}=$ Maximum total score for exposure that may occur in the back, shoulders / arms, wrists and neck. 


\section{Results and Discussion}

According to the results of the evaluation, the parts of the body most affected in performing the activities at the conveyor belt analysed are:

- Neck (by position)

- Hand and wrist (by position, frequency of movements and intensity of pressure)

- Back (by position, frequency and duration of movements).

And the causes of these diseases are:

- workers have a high and continuous work rate,

- repeated bending movements and rotation of the trunk with weight (pieces) in the hands,

- repeated gripping of the parts with the tips of the fingers,

which affects their spine (lumbar and cervical), wrists, elbows and shoulders.

The calculation of the Exposure Level is presented in the equation (2).

$$
\text { Exposure Level: } E(\%)=\frac{128}{176} \times 100 \%=72,72 \%
$$

Thus, the works performed by the operator were classified at the level that requires Investigations and immediate changes in the work situation. From the calculation of the exposure score, it can be seen that the neck score and torso score classified as very high level means that the risk is very high and can cause TTCs (Cumulative Traumatic Disorders), therefore the remedial is necessary either for the working position of the operator, or for the slowing down of the work pace and for exchanging places with other workers, or for work equipment (automation)..

\section{Conclusions}

In conclusion, the observation of the activities performed by a worker, in order to identify the ergonomic risk factors, lasts between 30 and 60 minutes, this also depending on the complexity of the activity, the anthropometric data of the workers and their experience in performing these activities correctly. The interview of the workers regarding the activities performed and the way they appreciate the answers to the questionnaire from Appendix 1, column 2, can take up to 30 minutes. The data obtained were entered in the corresponding matrices in Appendix 2 and the results were obtained immediately. Therefore, the application of QEC methodology is not complicated at all, but it requires increased attention, good organization and a good understanding of ergonomic risk factors.

To eliminate or reduce the impact of ergonomic risk factors on workers, following this assessment, a number of measures have been taken. One measure taken is to place the parts directly on the belt with the help of a conveyor and after that, the parts will be arranged manually by the workers. Another measure was the alternation (after 2 hours) of the band activities with other less physically demanding activities, as well as the training of the workers regarding the correct positions for handling and moving the parts, ie they will turn with their whole body, not just twist the trunk. As mentioned, Ergonomics is a science concerned with the "fit" between people and their work. Put people first, taking into account their abilities and limitations. It is important to understand that posture alone can cause / aggravate WRMSDS due to the weight of body segments if they are not supported or due to the end positions of the joints involved. When ergonomic rules are not followed, workers may suffer from musculoskeletal disorders, such as arthritis / osteoarthritis, hernia, tendinitis, tendinosis, etc. In other words, ergonomics aims to ensure that tasks, equipment, information and the environment are suitable for each worker. Based on this, each employee must understand the ergonomic risk factors related to his tasks and work 
solutions to minimize such risks namely awkward positions, static positions, excessive force, compression or contact stress, repetitive motions, psycho-social issues. To mitigate or eliminate these risks, we set goals for the implementation of ergonomic principles and by training and educating workers to comply with the rules of ergonomics. These will have the effect of increasing the welfare of workers and a better efficiency of productivity, therefore, an increase in the company's profit.

\section{References}

1. https://www.iso.org/obp/ui/\#iso:std:iso:26800:ed-1:v1:en, [Accessed 20.01.2021]

2. Simple Definition of ergonomics. Merriam-Webster, [Online]. Available: http://www.merriamwebster.com/dictionary/ergonomics, Accessed 20.01.2021]

3. M. J. Sanders, Ergonomics and the Management of Musculoskeletal Disorders, 2nd Edition, (Butterworth-Heinemann Books-Elsevier, 2003)

4. Ergonomics: Risk Factors. Blink. UC San Diego, [Online]. Available: https://blink.ucsd.edu/safety/occupational/ergonomics/, [Accessed 25.01.2021]

5. O.B. Krishna, J. Maiti, P.K. Ray, S. Mandal, Human Factors and Ergonomics in Manufacturing \& Service Industries, 25, 559 (2015)

6. C. Deeney, L. O'Sullivan, Work, 34, 239 (2009)

7. S. Yasobant, M. Chandran, E.M. Reddy, E. M. Are bus drivers at an increased risk for developing musculoskeletal disorders. An ergonomic risk assessment study. J Ergonom, S3:011, 1 (2015)

8. A. Colim, P. Carneiro, N. Costa, P. M. Arezes, N. Sousa, Ergonomic assessment and workstation design in a furniture manufacturing industry-a case study, (Occupational and Environmental Safety and Health -Springer International Publishing, 2019)

9. L. Punnett, D.H. Wegman, J Electromyogr Kinesiol, 14, 13 (2004)

10. https://www.profit.ro/povesti-cu-profit/auto-transporturi/analiza-romania-are-cea-maimare-pondere-a-angajatilor-din-productia-de-automobile-in-economie-dar-si-cel-maimic-numar-de-masini-noi-cumparate-din-ue-19461474, [Accessed 20.01.2021]

11. E.H. Sukadarin, B.M. Deros, J.A. Ghani, A.R. Ismail, M.M. Mokhtar, D. Mohamad, Current Trends In Ergonomics, (Book Series: Advanced Engineering Forum, v. 10, 2013)

12. R. Farhadi, L. Omidi, S. Balabandi, S. Barzegar, A.M. Abbasi, A.H. Poornajaf, M. Karchani, J Research Health, 4, 714 (2014)

13. I. Siregar, R. Fuad, Y. Hanifiah, PHICo 2016, Work Posture Assessment with Application (Quick Exposure Check) at Boiler Stations, (Medan, Indonesia, 2016)

14. G. David, V. Woods, G. Li, \& Buckle, APPL ERGON, 39 (2008)

15. E.O. Bulduk, S. Bulduk, T. Suren, Ovali, INT J IND ERGONOM, 44 (2014)

16. G.Y. Li, Buckle, A practical method for the assessment of work-related musculoskeletal risk-Quick exposure check (QEC). Proceedings Of The Human Factor And Ergonomics Society $42 \mathrm{Nd}$ Annual Meeting, v.1-2, (1998)

17. A.S.K. Cheng, P.C.V. So, Development of the Chinese version of the Quick Exposure Check (QEC), Work, 48, 503 (2014)

18. J.R.A. Bidiawati, E. Suryani, Procedia Manufacturing 4, 496 (2015)

19. S. Abazarpour, H.R. Mokhtarinia, Bakhshi, J REHABIL, 19, 302 (2019)

20. H.R. Mokhtarinia, S. Abazarpour, C.P. Gabel, Work -A Journal Of Prevention Assessment \& Rehabilitation, 67 (2020)

21. P. Ericsson, M. Björklund, \& Wahlström,. Work -A Journal Of Prevention Assessment \& Rehabilitation, 41, 5718 (2012) 
22. N. A. Ibrahim, S. A. S. A. Rahman, S. H. Ismail, H. Abdullah: Musculoskeletal Discomfort Evaluation using Quick Exposure Check (QEC) among Tower Crane Operators. 6th International Conference On Advances In Mechanical Engineering 2019 (ICAME) (Book Series: IOP Conference Series-Materials Science and Engineering, v.2019, 8)

23. S. Ramasamy, K. Adalarasu, T.N. Patel, Biomedical Research-India, 8 (2017)

24. R. Brown, G.Y. Li, The development of action levels for the 'quick exposure check' (QEC) system. Annual Conference of the Ergonomics-Society, Contemporary Ergonomics, (2003)

25. S. Oliv, E. Gustafsson, A.N. Baloch, M. Hagberg, E. Sanden, The Quick Exposure Check (QEC)-Inter-rater reability in total score and individual items, APPL ERGON, 76 (2019)

26. Ergonomic. Canadian Centre for Occupational Health \& Safety, [ONLINE]. Available: www.ccohs.ca/oshanswers/ergonomics. [Accessed 20 January 2021]

27. Further development of the usability and validity of the Quick Exposure Check (QEC). Prepared by University of Surrey for the Health and Safety Executive (2005)

28. J. Cuellar, C. Solís, J.M. Hernández and J.D. Velázquez, QEC Assessment Using at Cable Industry in Order to Prevent Musculoskeletal Disorders (MSD), [Online]. Available online https://lupinepublishers.com/medical-science-journal/fulltext/qecassessment-using-at-cable-industry-in-order-to-prevent-musculoskeletaldisorders.ID.000184.php, [Accessed 20 January 2021]

29. K. S. Tee, E. Low, H. Saim, W. N. W. Zakaria, S. B. M. Khialdin, H. Isa, M. I. Awad, and C. F. Soon. A study on the ergonomic assessment in the workplace (2017) 
Appendix 1

Worker's name

Date

\section{Observer's Assessment}

\section{Back}

A When performing the task, is the back (select worse case situation)

A1 Almost neutral?

A2 Moderately flexed or twisted or side bent?

A3 Excessively flexed or twisted or side bent?

B Select ONLY ONE of the two following task options:

\section{EITHER}

For seated or standing stationary tasks. Does the back remain in a static position most of the time?

B1 No

B2 Yes

\section{OR}

For lifting, pushing/pulling and carrying tasks

(i.e. moving a load). Is the movement of the back

B3 Infrequent (around 3 times per minute or less)?

B1 Frequent (around 8 times per minute)?

B5 Very frequent (around 12 times per minute or more)?

\section{Shoulder/Arm}

C When the task is performed, are the hands (select worse case situation)

C1 At or below waist height?

02 At about chest height?

C3 At or above shoulder height?

D Is the shoulder/arm movement

D1 Infrequent (some intermittent movement)?

D) Frequent (regular movement with some pauses)?

D3 Very frequent (almost continuous movement)?

\section{Wrist/Hand}

E Is the task performed with (select worse case situation)

E1 An almost straight wrist?

E2 A deviated or bent wrist?

F Are similar motion patterns repeated

F1 10 times per minute or less?

F2 11 to 20 times per minute?

F3 More than 20 times per minute?

\section{Neck}

G When performing the task, is the head/neck bent or twisted?

G1 No

G2 Yes, occasionally

G3 Yes, continuously

\section{Worker's Assessment}

\section{Workers}

H Is the maximum weight handled MANUALLY BY YOU in this task?

$\mathrm{H} 1 \quad$ Light (5 $\mathrm{kg}$ or less)

117 Moderate (6 to $10 \mathrm{~kg}$ )

$\mathrm{H} 3$

$\mathrm{H} 4$

Heavy (11 to $20 \mathrm{~kg}$ )

Very heavy (more than $20 \mathrm{~kg}$ )

J On average, how much time do you spend per day on this task?

11 Less than 2 hours

J) 2 to 4 hours

13 More than 4 hours

K When performing this task, is the maximum force level exerted by one hand?

K1 Low (e.g. less than $1 \mathrm{~kg}$ )

K2 Medium (e.g. 1 to $4 \mathrm{~kg}$ )

K3 High (e.g. more than $4 \mathrm{~kg}$ )

L Is the visual demand of this task

I Low (almost no need to view fine details)?

* L2 High (need to view some fine details)?

* If High. please give details in the box below

M At work do you drive a vehicle for

M1 Less than one hour per day or Never?

M2 Between 1 and 4 hours per day?

M3 More than 4 hours per day?

N At work do you use vibrating tools for

N1 Less than one hour per day or Never?

N2 Between 1 and 4 hours per day?

N3 More than 4 hours per day?

P Do you have difficulty keeping up with this work?

P1 Never

P2 Sometimes

*P'3 Often

* If Often, please give details in the box below

Q In general, how do you find this job

Q1 Not at all stressful?

Q2 Mildly stressful?

*Q3 Moderately stressful?

* 24 Very stressful?

* If Moderately or Very, please give details in the box below

* Additional details for $L, P$ and $Q$ if appropriate

* $\mathbf{L}$

* $\mathbf{P}$ 
Appendix 2

Exposure Scores Worker's name

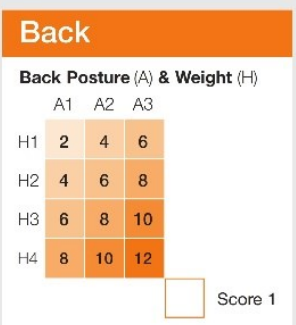

Back Posture (A) \& Duration (J)

A. A2 A3

\begin{tabular}{|c|c|c|c|}
\hline$J 1$ & 2 & 4 & 6 \\
\hline$\sqrt{ } 2$ & 4 & 6 & 8 \\
\hline$\sqrt{ } 3$ & 6 & 8 & 10 \\
\hline
\end{tabular}

Score 2

Duration $(J)$ \& Weight $(H\rangle$
$\begin{array}{llll}\pi & -2 & 0\end{array}$
$\begin{array}{llll}11 & 2 & 4 & 6\end{array}$
$\begin{array}{llll}12 & 4 & 6 & 8\end{array}$
$\begin{array}{llll}43 & 6 & 8 & 10\end{array}$
\begin{tabular}{ll|l|l}
-14 & 8 & 10 & 12
\end{tabular}

Score 3

Now do ONLY 4 if static

OR 5 and 6 if manual handling

Static Posture (B) \& Duration ( $\mathrm{J}$

\begin{tabular}{|c|c|c|}
\hline & B1 & B2 \\
\hline J1 & 2 & 4 \\
\hline J2 & 4 & 6 \\
\hline J3 & 6 & 8 \\
\hline
\end{tabular}

Score 4

Frequency $(\mathrm{B})$ \& Weight $(\mathrm{H})$

B3 B4 B5

$\begin{array}{llll}H 1 & 2 & 4 & 6\end{array}$

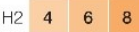

$\begin{array}{llll}13 & 6 & 8 & 10\end{array}$

\begin{tabular}{|l|l|l|l|}
14 & 8 & 10 & 12
\end{tabular}

Score 5

Frequency $(\mathrm{B})$ \& Duration $(\mathrm{J})$

B3 B4 B5

\begin{tabular}{ll|l|l|} 
J1 & 2 & 4 & 6
\end{tabular}

J2 $44 \quad 6 \quad 8$

\begin{tabular}{l|l|l|l} 
J3 & 6 & 8 & 10
\end{tabular}

Score 6

Total score for Back

Sum of scores 1 to 4 OR

Scores 1 to 3 plus 5 and

\section{Shoulder/Arm}

Height $(\mathrm{C})$ \& Weight $(\mathrm{H})$ $\begin{array}{llll}\mathrm{C} 1 & \mathrm{C} 2 & \mathrm{C} 3\end{array}$

$\begin{array}{lllll}\mathrm{H} 1 & 2 & 4 & 6\end{array}$

\begin{tabular}{l|l|l|l|}
$\mathrm{H} 2$ & 4 & 6 & 8
\end{tabular}

\begin{tabular}{l|l|l|l} 
H3 & 6 & 8 & 10
\end{tabular}

\begin{tabular}{l|l|l|l|}
$\mathrm{H} 4$ & 8 & 10 & 12
\end{tabular}

Height (C) \& Duration (J) $\begin{array}{lll}\mathrm{C} 1 & \mathrm{C} 2 & \mathrm{C} 3\end{array}$

$\begin{array}{llll}J 1 & 2 & 4 & 6\end{array}$

\begin{tabular}{l|l|l|l}
$\mathrm{J} 2$ & 4 & 6 & 8
\end{tabular}

\begin{tabular}{l|l|l|l|} 
J3 & 6 & 8 & 10
\end{tabular} Score 2

Duration $(\mathrm{J})$ \& Weight $(\mathrm{H})$

$$
\begin{array}{|c|c|c|c|}
\hline & \text { J1 } & \text { J2 } & \text { J3 } \\
\hline \mathrm{H} 1 & 2 & 4 & 6 \\
\hline \mathrm{H} 2 & 4 & 6 & 8 \\
\hline \mathrm{H} 3 & 6 & 8 & 10 \\
\hline \mathrm{H} 4 & 8 & 10 & 12 \\
\hline
\end{array}
$$

Score 3

Frequency $(\mathrm{D})$ \& Weight $(\mathrm{H})$

D1 D2 D3

\begin{tabular}{|c|c|c|c|}
\hline $\mathrm{H} 1$ & 2 & 4 & 6 \\
\hline $\mathrm{H} 2$ & 4 & 6 & 8 \\
\hline $\mathrm{H} 3$ & 6 & 8 & 10 \\
\hline $\mathrm{H} 4$ & 8 & 10 & 12 \\
\hline
\end{tabular}

Score 4

Frequency (D) \& Duration (J) D1 D2 D3

$\begin{array}{llll}J 1 & 2 & 4 & 6\end{array}$

\begin{tabular}{l|l|l|l|}
$\mathrm{J} 2$ & 4 & 6 & 8 \\
\hline
\end{tabular}

\begin{tabular}{|l|l|l|l|}
$\sqrt{3} 3$ & 6 & 8 & 10
\end{tabular} Score 5

Total score for Shoulder/Arm Sum of Scores 1 to 5
Date

\section{Wrist/Hand}

Repeated Motion (F) \& Force $(\mathrm{K})$ F1 F2 F3

\begin{tabular}{ll|l|l}
$\mathrm{K} 1$ & 2 & 4 & 6
\end{tabular}

\begin{tabular}{l|l|l|l}
$\mathrm{K} 2$ & 4 & 6 & 8
\end{tabular}

\begin{tabular}{l|l|l|l|}
$\mathrm{K} 3$ & 6 & 8 & 10
\end{tabular} Score 1

Repeated Motion (F) \& Duration (J) $\begin{array}{llll}\text { F1 } & \text { F2 } & \text { F3 }\end{array}$

$\begin{array}{llll}11 & 2 & 4 & 6\end{array}$

\begin{tabular}{l|l|l|l} 
J2 & 4 & 6 & 8
\end{tabular}

\begin{tabular}{l|l|l|l|} 
J3 & 6 & 8 & 10
\end{tabular} Score 2

Duration $\langle J\rangle$ \& Force $(K)$

$$
\begin{array}{lll}
\mathrm{J} 1 & \mathrm{~J} 2 & \mathrm{~J} 3
\end{array}
$$

$\begin{array}{llll}\text { K1 } & 2 & 4 & 6\end{array}$

\begin{tabular}{ll|l|l}
$\mathrm{K} 2$ & 4 & 6 & 8
\end{tabular}

\begin{tabular}{l|l|l|l}
$\mathrm{K} 3$ & 6 & 8 & 10
\end{tabular} Score 3

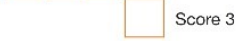

Wrist Posture (E) \& Force (K)

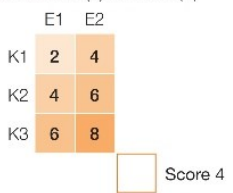

Wrist Posture (E) \& Duration (J)

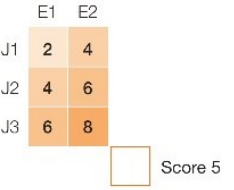

Total score for Wrist/Hand Sum of Scores 1 to 5

$$
\begin{array}{l|l|l}
1 & 4 & 9
\end{array}
$$$$
\text { P1 P2 P3 }
$$

Total for Work pace

\section{Stress}

G1 G2 G3

$\begin{array}{llll}\text { J1 } & 2 & 4 & 6\end{array}$

\begin{tabular}{ll|l|l} 
J2 & 4 & 6 & 8
\end{tabular}

\begin{tabular}{l|l|l|l|} 
J3 & 6 & 8 & 10
\end{tabular} Score 1

Visual Demand (L) \& Duration (J)

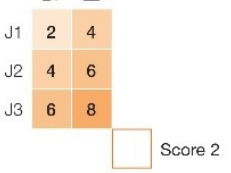

total score for Neck

\section{Driving}

M1 M2 M3

$$
\begin{array}{l|l|l}
1 & 4 & 9
\end{array}
$$

Total for Driving

\section{Vibration}

$$
\begin{array}{c|c|c|}
\text { N1 } & \text { N2 } & \text { N3 } \\
\hline 1 & 4 & 9
\end{array}
$$

Total for Vibration

\section{Work pace}

Q1 Q2 Q3 $\quad$ Q4

\begin{tabular}{ll|l|l}
1 & 4 & 9 & 16
\end{tabular}

Total for Stress 